\title{
A REDESCRIPTION OF GEGENEOPHIS CARNOSUS (BEDDOME, 1870) (AMPHIBIA: GYMNOPHIONA)
}

\author{
G.M. Malathesh, K.R. Gundappa, S. Ravichandra Reddy and Katre Shakuntala \\ Department of Zoology, Bangalore University, Jnana Bharathi, Bangalore, Karnataka 560056, India.
}

\begin{abstract}
Eight specimens of the lesser known Gegeneophis carnosus (Beddome) sighted and collected during JuneSeptember 1996 from the General Cariappa Biodiversity Park at Madikeri, Karnataka State, India are redescribed with details of their morphology, rnorphometry and comparative taxonomic analysis. The species appears to be an altitudinal one, restricted in its distribution to the wet semi-evergreen forest range of the Western Ghat belt of Kerala and Karnataka and inhabits a unique cryptic subterranean habitat.
\end{abstract}

\section{Keywords}

Amphibia, Gegeneophis carnosus, redescription, Biodiversity Park, Madikeri

\section{Introduction}

Gegeneophis carnosus was first discovered at Peria Peak in Wyanad, Malabar, (Beddome, 1870) and subsequently recorded at the foot of Ponmudi Hill ranges, Kallar, Kerala (Ferguson, 1904; Inger et al., 1984), by the side of small water courses on the hillside in Tenmalai, Travancore (Seshachar, 1942), at Kotagehar, in the Kodagu region of Karnataka, (Ramaswami, 1943; Seshachar \& Ramaswami, 1943), at Bonnakad Estate, Kerala and at Palode, near Thiruvananthapuram (Pillai \& Ravichandran, 1999). However, observations on ecology and morphology of the species remain incomplete. The present paper redescribes the species from specimens collected from General Cariappa Biodiversity Park, Madikeri, Kodagu District, Karnataka. These specimens are deposited in the Museum of Aqua Laboratory, Department of Zoology (MALZ 9601 to 9608), Bangalore University, Jnana Bharathi, Bangalore.

\section{Materials and Methods}

Specimens of Gegeneophis carnosus were collected during June, August and September 1996 from the clayey regions under thick vegetation found along small streams in the Cariappa Biodiversity Park, Madikeri (1143.3m). By carefully digging the clay around the root system of shrubs, individuals were located and hand picked. These microhabitats had porous soil with continuous gradient seepage of water. The soil was rich in humus and the $\mathrm{pH}$ ranged from 5.5. to 6.0. Specimens of medium-sized earthworms (Pheretima sp.) and on one occasion, an unidentified species of an adult caecilian (Ichthyophis sp.) were also encountered in the same habitat. Extensive soil excavations by wild boar were a frequent sight during the search for this caecilian. Soon after collection, the specimens were transferred to polyethylene containers along with small amount of soil. Upon return to the laboratory, the animals were anaesthetized and preserved in $70 \%$ alcohol and each tagged with a separate number. Using slide calipers morphometric measurements of the specimens were made.

\section{Results and Observations Morphology}

Colouration: Live specimens are generally pinkish-red, slightly darker on the dorsum than on the venter. The head and collars are distinctly lighter, yellowish-pink. The snout and jaws are characteristically light yellow being lighter than the rest of the body. Such a body colouration of G. carnosus has also been reported by Daniel (1963) and Taylor (1968). On preservation in $70 \%$ alcohol however, the above colouration was lost and the body was rendered mottled with light olive dorsally and light greyish-cream ventrally. Two distinct dark patches are present on dorsal region of head, one each on either side of the median line. Eyes are hardly visible as spots, embedded in the bone of skull. 


\section{Description}

Head oval, slender, snout projecting beyond mouth (Fig. 1), eyes hardly visible, buried under skull bone. Tentacular area distinctly swollen (Fig. 2), foramen not visible from above. Nostrils nearly terminal, not visible from directly above the head. Tentacular foramen situated below and behind nostril. Two collars delineated by first and second and third nuchal grooves, a small incomplete dorsal groove apparent in anterior, smaller collar especially in preserved specimens; posterior collar larger, complete above, partially divided by a transverse groove, which courses laterally and fuses with first primary annulus ventrolaterally. Posterior to collars, are distinct primary annuli followed by secondary annuli. All primary annuli are complete above and below and grooves are apparent only on microscopic observation and/or on preservation in alcohol. In preserved specimens, body surface, especially dorsal surface of primaries exhibits pigmentation, suggesting a faint, warty glandular surface. Posterior to primaries are, seven secondaries of which anterior four are complete. The posterior terminus of body is covered with an unsegmented shield. On the ventral side of shield is the transverse vent (Fig. 3). Area of vent is markedly translucent, whitish in colour and vent is bordered by denticles all around; the shield narrows teminally; no tail.

\section{Morphometry}

Data on the morphometry of the eight specimens collected are given in Table 1 . The longest specimen measures $226 \mathrm{~mm}$ with a body width of $<6 \mathrm{~mm}$ indicating that it is a slender species compared to other caecilians recorded from southern India (Taylor, 1968; Balakrishna et al., 1982a, 1982b). The width in length ranged between 35-41 and head-length surpasses headwidth.

Of the eight specimens collected, only one (MALZ 1906M) is a male, showing an everted phallodeum (Fig. 4). As this specimen measures $205 \mathrm{~mm}$ in total length, it is presumed that, of the other seven specimens collected, at least two (MALZ 9607 and 9608) which measure $>205 \mathrm{~mm}$ but do not exhibit phallodeal eversion could be considered as females, while the remaining five, measuring $<205 \mathrm{~mm}$ are either immature males or females. The study of Taylor $(1961,1968)$ on this species was based on individuals measuring only $162-172 \mathrm{~mm}$ and he was also doubtful of their maturity.

Table 2 presents data on the details of body folds and morphometric measurements of individuals collected. The total number of body folds in each of the eight specimens ranged from 109 to 118 . While the primaries ranged from 101 to 110 , the secondaries were always seven, with a single terminal shield. Width of the second collar always surpasses that of the first. Tentacle is located closer to the nostril.

\section{Dentition}

Details of teeth rows and measurement of teeth are in Table 3. There are four dental series, all teeth recurved posteriorly. In the upper jaw, the outer premaxillary - maxillaries are 11-1-11 of

Table 1. Gross morphometric measurements (in $\mathrm{mm}$ ) of Gegeneophis carnosus

\begin{tabular}{|c|c|c|c|c|c|c|c|c|}
\hline Parameters & $9601(\mathrm{IM})$ & 9602 (IM) & $9603(\mathrm{IM})$ & $9604(F)$ & $9605(F)$ & $9606(M)$ & $9607(\mathrm{~F})$ & $9608(F)$ \\
\hline Total length & 133.00 & 138.00 & 155.00 & 186.00 & 197.00 & 205.00 & 210.00 & 226.00 \\
\hline Body width at the widest region & 3.88 & 3.96 & 4.22 & 5.04 & 5.04 & 5.06 & 5.84 & 5.58 \\
\hline Width in length (times) & 35.00 & 35.38 & 36.91 & 36.91 & 39.01 & 36.48 & 35.91 & 40.68 \\
\hline Head length & 4.00 & 4.47 & 4.47 & 4.70 & 4.86 & 4.23 & 4.47 & 4.23 \\
\hline Head Width & 3.06 & 3.43 & 3.43 & 3.53 & 3.76 & 4.01 & 4.04 & 3.76 \\
\hline Posterior terminal width & 3.24 & 3.36 & 3.74 & 4.56 & 3.72 & 4.08 & 5.10 & 4.50 \\
\hline Snout length & 0.94 & 0.94 & 0.94 & 0.94 & 1.04 & 1.18 & 0.94 & 1.18 \\
\hline Terminal shield length & 1.88 & 2.12 & 2.35 & 2.12 & 1.88 & 3.01 & 2.35 & 3.06 \\
\hline Terminal shield width & 1.41 & 1.88 & 1.88 & 1.41 & 1.41 & 2.35 & 1.88 & 2.35 \\
\hline Length of throat & 3.06 & 3.29 & 3.29 & 4.23 & 4.00 & 4.00 & 4.00 & 3.76 \\
\hline Length of cloacal area & 0.94 & 1.18 & 1.18 & 1.41 & 1.64 & N.R. & 1.80 & 1.52 \\
\hline Width of cloacal area & 0.94 & 1.18 & 1.18 & 1.60 & 1.41 & N.R. & 1.80 & 1.41 \\
\hline
\end{tabular}

Malz: Museum of the Aqua Lab, Department of Zoology, Bangalore University.

IM - Immature individual. F- Female, M - Male, N.R. - Not recorded due to everted cloaca. 


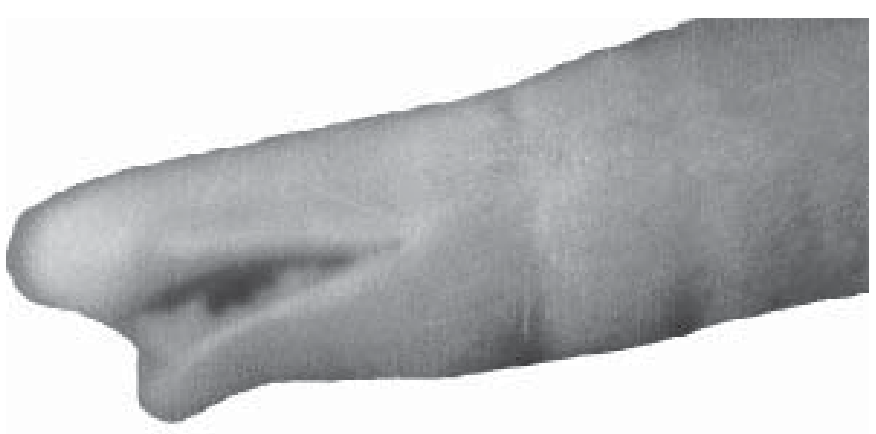

Figure 1. Lateral view of Gegeneophis carnosus showing the anterior part

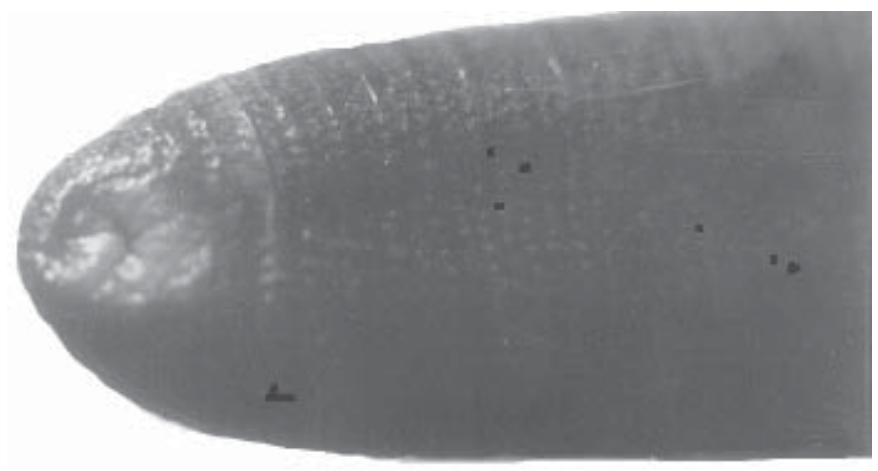

Figure 3. Ventral view of female Gegeneophis carnosus showing the vent

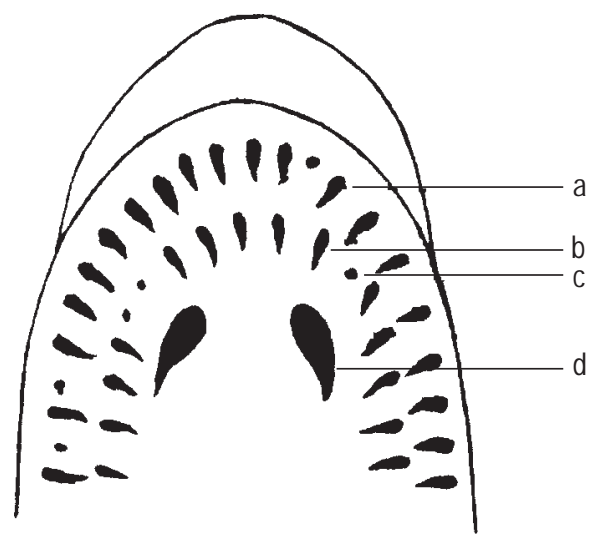

Figure 5. Details of dentition in the upper jaw. a. outer row of premaxillary-maxillary teeth (11-1-1); b. Inner row of prevomero-palatine teeth (8-1-8); c. Vacant space to indicate loss of tooth; $d$. Choanae.

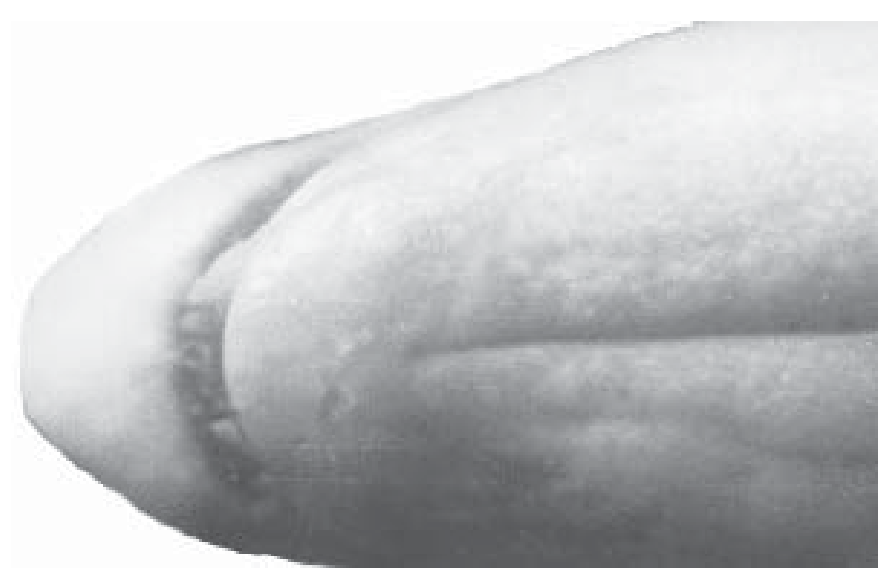

Figure 2. Ventral view of Gegeneophis carnosus showing swollen tentacular area

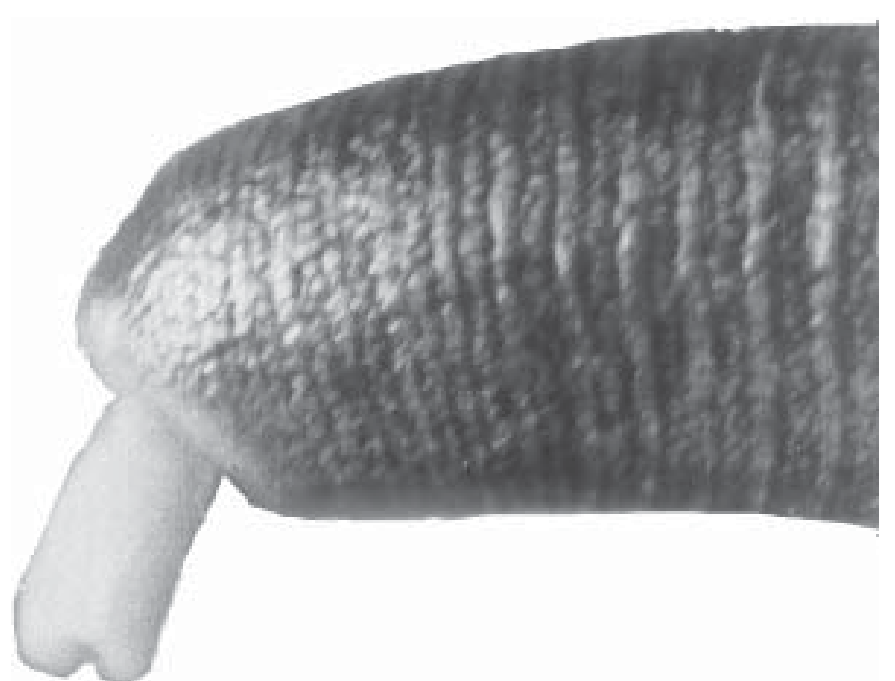

Figure 4. Lateral view of male Gegeneophis carnosus showing everted phallodium

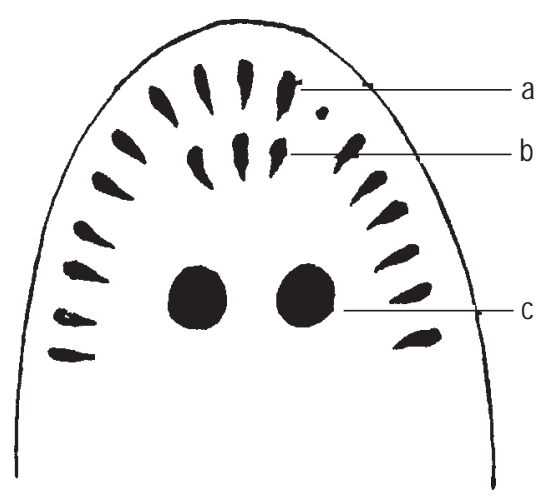

Figure 6. Details of dentition in the lower jaw. a. Outer row of dentaru teeth (8-1-8); $b$. Inner row of splenial teeth (1-1-1); c. Narial plug on the tongue. 
Table 2. Details of annuli and morphometric measurements (linear: $\mu \mathrm{m}$ ) of Gegeneophis carnosus.

\begin{tabular}{lllllllll}
\hline Parameters & $9601(\mathrm{IM})$ & $9602(\mathrm{IM})$ & $9603(\mathrm{IM})$ & $9604(\mathrm{~F})$ & $9605(\mathrm{~F})$ & $9606(\mathrm{M})$ & $9607(\mathrm{~F})$ & $9608(\mathrm{~F})$ \\
\hline Total number of folds & 110 & 114 & 118 & 109 & 114 & 114 & 115 & 116 \\
Number of primary annuli & 102 & 106 & 110 & 101 & 106 & 106 & 107 & 108 \\
Number of secondary annuli & 7 & 7 & 7 & 7 & 7 & 7 & 7 & 1 \\
Terminal shield & 1 & 1 & 1 & 1 & 1 & 1 & 4 & 4 \\
Tip of snout to I nuchal groove & 3995 & 4465 & 4465 & 4700 & 4860 & 4230 & 4950 & 4230 \\
Tip of snout to II nuchal groove & 5170 & 5875 & 5875 & 6110 & 6390 & 6510 & 6830 & 6510 \\
Tip of snout of I primary annual groove & 8050 & 7755 & 8225 & 8460 & 8640 & 9095 & 9180 & 9095 \\
Width of I collar & 1175 & 1410 & 1416 & 1410 & 1530 & 2280 & 1880 & 2280 \\
Width of II collar & 1880 & 1880 & 2350 & 2350 & 2250 & 2585 & 2350 & 2585 \\
Average width of each primary & 940 & 1410 & 1551 & 1551 & 1551 & 1551 & 2040 & 1645 \\
Average width of each secondary annulus & 705 & 940 & 940 & 1410 & 940 & 940 & 960 & 658 \\
Distance between eye and tentacle & 940 & 940 & 1880 & 1410 & 1880 & 1880 & 1880 \\
Distance between tentacle and nostril & 470 & 658 & 940 & 893 & 705 & 846 & 940 & 7045 \\
\hline
\end{tabular}

Table 3. Details of dentition and choanae of Gegeneophis carnosus.

\begin{tabular}{|c|c|c|c|c|c|c|}
\hline Jaws & Teeth rows & $\begin{array}{l}\text { Distance between the } \\
\text { two teeth rows }(\mu \mathrm{m})\end{array}$ & $\begin{array}{l}\text { Average number } \\
\text { of teeth }\end{array}$ & $\begin{array}{l}\text { Distance between two } \\
\text { successive teeth }(\mu \mathrm{m})\end{array}$ & $\begin{array}{l}\text { Avg. length / width } \\
\text { of each tooth }(\mu \mathrm{m})\end{array}$ & $\begin{array}{l}\text { Distance between } \\
\text { two choanae }(\mu \mathrm{m})\end{array}$ \\
\hline \multirow[t]{2}{*}{ Upper } & Outer Premaxillary maxillary & 600 & $11-1-11$ & 144 & $240 / 72$ & 600 \\
\hline & Inner Prevomeropalatine & 600 & 8-1-8 & 144 & $240 / 72$ & \\
\hline Lower & Outer Dentary & 360 & 8-1-8 & 120 & Anterior larger 360/96 & \\
\hline
\end{tabular}

which 4-1-4 are premaxillaries and 7-7 are maxillaries. The inner prevomeropalatines are 8-1-8 of which 4-1-4 are prevomerines and 4-4 are palatines. The distance between these two rows of teeth is about $600 \mu \mathrm{m}$ and the distance between two successive teeth is about $144 \mu \mathrm{m}$. The average length/width of each tooth in both rows is about 240/72um respectively. In the lower jaw, the anterior (except 1-1-1) teeth in the outer dentary are the largest, with tooth size diminishing posteriorly. The premaxillary and maxillary teeth are the second largest, and even among these, the premaxillary ones are more exposed than the maxillary ones. There is no size difference between the anterior and posterior teeth of these rows. The prevomero-palatine teeth are of the same size as the premaxillary and maxillary. The splenial teeth are similar to prevomero-palatine, both being distinctly smaller than the dentary. On closure of the two jaws, the upper jaw projects over the lower with the premaxillary-maxillary teeth overlying the dentary. In all eight specimens, in the four series of teeth, tooth loss is evident from their loci (Figs. 5-6).

\section{Tongue}

The fleshy tongue bears two globular narial plugs. The narial plugs are located in deep cavities, their upper surfaces are on level with the surface of the tongue. The diameter of one narial plug in the distance between them is $>3$ times. The choanae are directed outwards and forwards (Fig. 5).

\section{Phallodeum}

The everted phallodeum is pear-shaped, pale in colour, with distinct vertical ridges (about 5-6 rows on each side). The diameter is around $1786 \mu \mathrm{m}$ and length $2397 \mu \mathrm{m}$. The terminal 


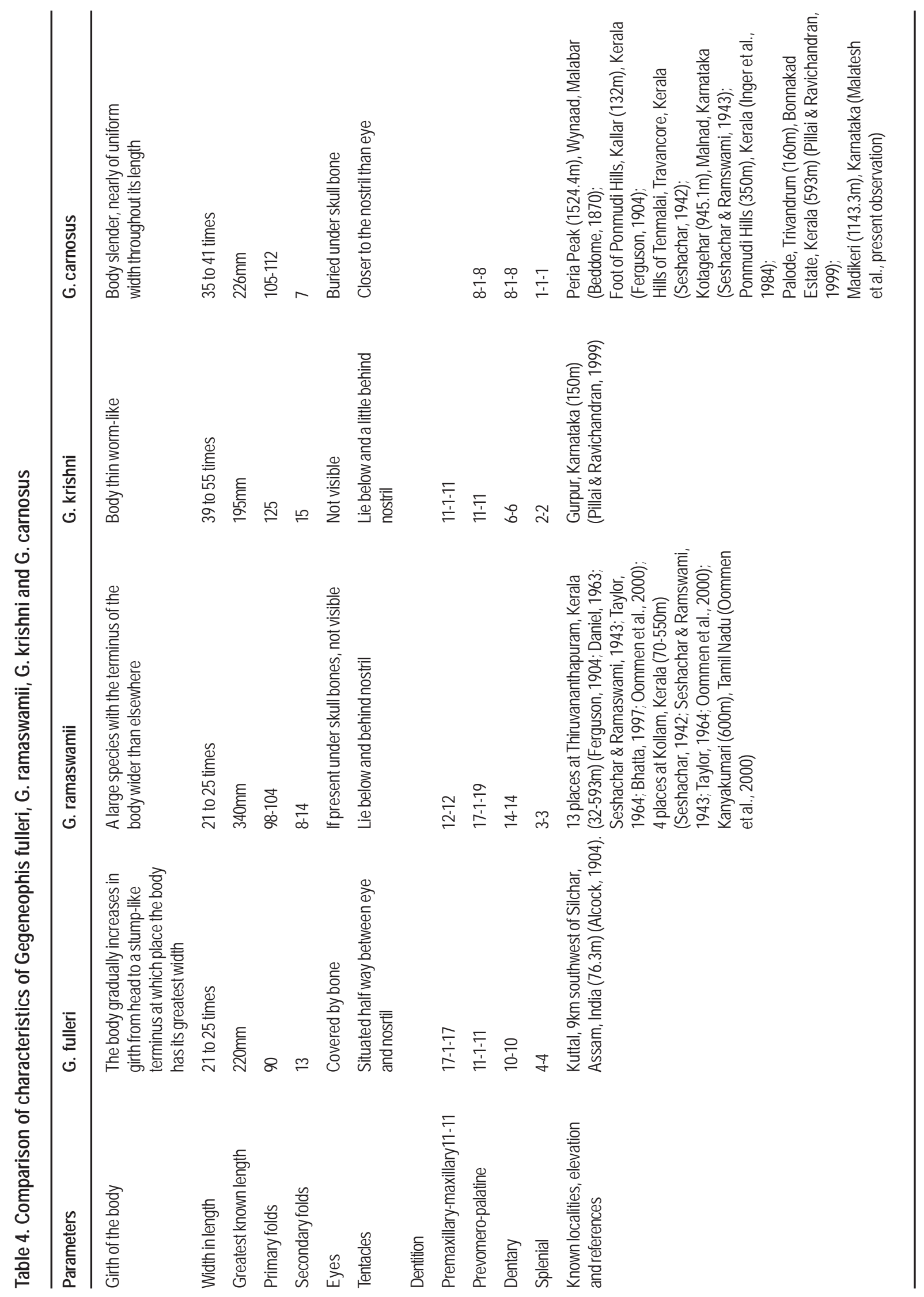


aperture width is about $864 \mu \mathrm{m}$ (Fig. 4).

\section{Diagnosis and distribution of the species}

The specimens collected at Madikeri and as described above have been diagnosed as Gegeneophis carnosus (Beddome), after comparison with specific characters of other species of the genus Gegeneophis (Table 4). The redescription of G. carnosus as detailed in this paper clearly distinguishes it from other species of Gegeneophis, especially in the pattern of dentition and few other morphometric characters. The distribution of G. carnosus appears to have an altitudinal range extending from $150 \mathrm{~m}$ (Seshachar, 1942) to $1524.4 \mathrm{~m}$ (Beddome, 1870) and is restricted to the wet semi-evergreen forests of the Western Ghats of Kerala and Karnataka, southern India. This distribution is perhaps influenced by climatic conditions (see also Daniel, 1963).

\section{References}

Alcock, A.W. (1904). Description and reflection upon a new species of apodus amphibian from India. Annals of the Magazine of Natural History 7(14): 267-273.

Balakrishna, T.A., K.R. Gundappa and K. Shakuntala (1982a). A note on the occurrence and habitat features of Ichthyophis beddomei (Peters) and Uraeotyphlus narayani (Seshachar). Current Science 51(17): 415-416.

Balakrishna, T.A., K. Shakuntala and K.R. Gundappa (1982b). Taxonomy and myogen pattern of some caecilians of the Indian subcontinent. Current Science 51(17): 848-849.

Beddome, R.H. (1870). Descriptions of new reptiles from the Madras Presidency. Madras Monthly Journal of Medical Science 2: 169-176.

Bhatta, G. (1997). Caecilian diversity of the Western Ghats: In search of the rare animals. Current Science 73(2): 183-187.
Daniel, J.C. ( 1963). Field guide to the amphibians of Western India. Part -1. Journal of the Bombay Natural History Society 60(2): 415-438.

Ferguson, H.S. (1904). A list of Travancore batrachians. Journal of the Bombay Natural History Society 15: 499-509.

Inger, R.F., H.B. Shaffer, M. Koshy and R. Bakde (1984). A report on a collection of amphibians and reptiles from Ponmudi, Kerala, South India. Journal of the Bombay Natural History Society 81/2: 406-570.

Oommen O.V., J.G. Measey, D.J. Gower and M. Wilkinson (2000). Distribution and abundance of the caecilian Gegeneophis ramaswamii. Current Science 79(9): 1386-1389.

Pillai, R.S. and M.S. Ravichandran (1999). Gymnophiona (Amphibia) of India: A taxonomic study. Records of the Zoological Survey of India 172: 1-117.

Ramaswami, L.S. (1943). An account of the head morphology of Gegeneophis carnosus (Beddome) Apoda. Journal of Mysore University 3: 205-222.

Seshachar, B.R. (1942). The eggs and embryos of Gegenophis carnosus (Beddome). Current Science 11: 439-441.

Seshachar, B.R. and L.S. Ramaswami (1943). Gegeneophis carnosus (Beddome) from South India. Journal of Mysore University 4: 111-113.

Taylor, E.H. (1960). A new caecilian genus in India. University of Kansas Science Bulletin 40(3): 31-36.

Taylor, E.H. (1961). Notes on Indian Caecilians. Journal of the Bombay Natural History Society 58(2): 355-365.

Taylor, E.H. (1964). A new species of caecilian from India (Amphibia, Gymnophiona). Senck Biologie 45(3/5): 227-231.

Taylor, E.H. (1968). The Caecilians of the World, A Taxonomic Review. University of Kansas Press, Lawrence, 848pp. 